\title{
ANÁLISE DAS HABILIDADES AUDITIVAS EM UMA CRIANÇA DEFICIENTE AUDITIVA ORALIZADA E PORTADORA DE HIV: ESTUDO DE CASO
}

\author{
Hearing abilities and analysis in an oralized \\ hearing-impaired child with HIV: a case study
}

Francine Nolasco Bastos ${ }^{(1)}$, Raquel Fleig ${ }^{(2)}$, Iramar Baptistella do Nascimento ${ }^{(3)}$

\begin{abstract}
RESUMO
Tema: habilidades auditivas em criança portadora de Vírus da Imunodeficiência Humana (HIV). Procedimentos: se a perda de audição não for detectada precocemente, assim como a sua etiologia, a criança terá muitos prejuízos no desenvolvimento da linguagem. Um fator que vem aumentando os índices de deficiência auditiva é a grande dose de medicamentos que os portadores de Vírus da Imunodeficiência Humana (HIV) devem ingerir para o controle da doença. Durante o processo de desenvolvimento da audição, o indivíduo passa pela aquisição das habilidades auditivas, que ocorrem em diferentes etapas do processo terapêutico, sendo elas: detecção, discriminação, reconhecimento auditivo introdutório, reconhecimento auditivo avançado e compreensão. Com o objetivo descrever e caracterizar as habilidades auditivas presentes em uma criança com perda auditiva inserida na abordagem oral, a pesquisa foi caracterizada como relato de caso. A criança fazia uso de dispositivo auditivo e frequentava atendimento fonoaudiológico na Clínica de Fonoaudiologia da Faculdade Estácio de Sá de Santa Catarina, em estágio supervisionado em audiologia educacional. Para coleta de dados foram filmadas quatro sessões de fonoterapia, visando a observação da presença ou ausência das habilidades auditivas. Resultados: verificou-se que as habilidades auditivas de detecção, discriminação e reconhecimento auditivo introdutório estão presentes no indivíduo da pesquisa e as habilidades auditivas de reconhecimento auditivo avançado e compreensão estão em etapa de desenvolvimento, e, portanto, ausentes. Conclusão: o desenvolvimento das habilidades auditivas é imprescindível para a aquisição da linguagem oral do deficiente auditivo.
\end{abstract}

DESCRITORES: Perda Auditiva; HIV; Linguagem

\section{INTRODUÇÃO}

A audição é essencial para o desenvolvimento da fala e da linguagem. Segundo dados da Organização Mundial da Saúde ${ }^{1}$ (World Health Organization, 2006), $10 \%$ da população mundial tem algum déficit auditivo. Já, a deficiência auditiva de grau

(1) Fonoaudióloga; Clínica Climed e Ciência, Florianópolis, SC.

(2) Fonoaudióloga; Docente do Curso de Fonoaudiologia da Faculdade Estácio de Sá de Santa Catarina, FESSC, São José, SC; Mestre em Engenharia de Produção (Ergonomia).

(3) Fisioterapeuta; Docente da Universidade do Sul de Santa Catarina, UNISUL, Florianópolis, SC; Mestre em Engenharia de Produção (Ergonomia).

Conflito de interesses: inexistente severo ou profundo incide em uma a cada mil pessoas nos países desenvolvidos e em quatro a cada mil pessoas em países subdesenvolvidos. No Brasil, calcula-se que 15 milhões de homens e mulheres tenham algum tipo de perda auditiva e 350 mil nada ouçam ${ }^{1}$.

Em uma criança, a perda auditiva é qualquer grau de audição que reduza a inteligibilidade da mensagem falada a um grau de inadequação para a interpretação apurada ou para a aprendizagem ${ }^{2}$.

Dentre as várias etiologias da deficiência auditiva, a Síndrome da Imunodeficiência Adquirida (HIV) deve ser destacada ${ }^{3,4}$, visto que a elevada dose de medicamentos ingeridos pelos portadores desse vírus acaba lesionando as células da cóclea do sistema auditivo, ocasionando, dessa forma, a 
perda auditiva de forma gradativa. Alguns autores realizaram um relato de caso com uma criança portadora do Vírus da Imunodeficiência Humana (HIV) há dois anos, e, desde então, fazia uso do coquetel medicamentoso para controle da doença. No exame audiométrico, acusou perda auditiva neurossensorial de grau moderado à orelha esquerda e perda auditiva mista de grau severo a profundo à orelha direita. Por esse motivo, os autores concluíram que a detecção precoce da perda auditiva é um fator importante para melhor controle da progressão da doença, indicação de fonoterapia e adaptação de próteses auditivas ${ }^{4}$.

O uso do Aparelho de Amplificação Sonora Individual (AASI), ou prótese auditiva, tem como finalidade primária a amplificação sonora mais adequada e satisfatória possível, incluindo os sons da fala, os sons ambientais, sinais de perigo e alerta, bem como os sons que melhoram a qualidade de vida do indivíduo, como a música, o canto dos pássaros, entre outros, e facilitar a educação e o desenvolvimento psicossocial e intelectual do deficiente auditivo ${ }^{5}$.

Existem vários fatores que influenciam no desenvolvimento da linguagem de uma criança deficiente auditiva. São eles: época do diagnóstico, época da aquisição dos aparelhos auditivos ou implante coclear, idade em que se inicia a terapia fonoaudiológica e sua duração, aspectos intelectuais, emocionais e atitude familiar ${ }^{6}$.

Pesquisadoras da Universidade Federal de Santa Maria ${ }^{7}$ realizaram um estudo que demonstra a importância da função auditiva para o desenvolvimento da linguagem. Avaliaram 19 crianças de seis a 18 meses de idade que frequentavam o ambulatório de Audiologia do Hospital Universitário de Santa Maria e que estavam com as respostas auditivas comportamentais alteradas em relação à idade cronológica. Evidenciaram que $42,1 \%$ das crianças avaliadas apresentaram desempenho da linguagem inadequado, concluindo que a integridade do sistema auditivo é fundamental para o desenvolvimento da linguagem.

Um estudo ${ }^{8}$ mediu o efeito do grau de perda auditiva sobre o grau de perda de vocabulário, consciência fonológica e desempenho escolar em 34 escolares da primeira série de oito escolas pública, de sete anos de idade com perda auditiva em pelo menos uma orelha. Essas crianças foram comparadas a outras 34 sem perda auditiva e verificaram que quanto maior o grau de perda auditiva, menor o vocabulário, a consciência fonológica, a discriminação auditiva e a nota escolar, e maior a incidência de dificuldades articulatórias e de trocas e omissões articulatórias.
Os objetivos iniciais a serem alcançados com a terapia fonoaudiológica são as habilidades auditivas: detecção, discriminação, reconhecimento e compreensão ${ }^{9}$. Desenvolver as habilidades auditivas levará a criança ao aprendizado da linguagem oral, bem como ao da compreensão e ao da atribuição de significado que ela possa dar ao mundo.

Com o objetivo de verificar a importância do desenvolvimento das habilidades auditivas no processo de desenvolvimento da linguagem oral ${ }^{10}$, realizou-se um estudo com seis crianças deficientes auditivas, que fazem uso de prótese auditiva ou Implante Coclear. As autoras aplicaram um questionário aos pais ou responsáveis que tinha por objetivo verificar o histórico do desenvolvimento da criança. Também fizeram filmagens e gravações para verificar o repertório verbal e analisar o desenvolvimento fonológico das crianças em estudo. Quanto aos resultados do questionário, observou-se que todas as crianças tiveram um atraso no desenvolvimento da linguagem, minimizado em uma criança protetizada aos cinco meses, o que foi mostrado, também, pelas gravações, concluindo o quão é importante estimular os comportamentos linguísticos e auditivos, o mais precocemente possível, para o desenvolvimento da linguagem.

Habilidades auditivas ${ }^{11}$ :

- detecção: é a habilidade auditiva em que a criança deve perceber a presença e ausência do som;

- discriminação: é o ato de diferenciar dois ou mais estímulos sonoros;

- reconhecimento: é a habilidade de identificar o som e a fonte sonora com capacidade de classificar ou nomear o que ouviu;

- compreensão: é o ato de estabelecer relações entre o estímulo sonoro produzido, outros eventos do ambiente e o próprio comportamento. Essas relações têm as propriedades de reflexividade, simetria e transitividade.

O trabalho com detecção tem os seguintes objetivos: determinar se a prótese auditiva está funcionando bem, ajudar a criança a aprender e a se descobrir, e preparar a criança para os níveis mais refinados das habilidades auditivas. Assim que a criança consegue detectar o som, o trabalho deve focar a discriminação auditiva, estimulando a criança a diferenciar os seguintes sons: vogais, traços distintivos de consoantes, palavras, frases e curvas melódicas ${ }^{12}$.

O reconhecimento auditivo ocorre em duas etapas: a primeira é a etapa introdutória, onde os estímulos são apresentados em conjunto fechado (closed-set); e a segunda etapa é o reconhecimento auditivo avançado, na qual são apresentados estímulos auditivos em conjunto aberto (open-set) ${ }^{9}$. 
O reconhecimento representa o início da habilidade de compreensão, conseqüentemente, pressupõe todos os níveis de processamento auditivo, a saber: detecção, discriminação, reconhecimento introdutório e avançado, envolvendo os processos psíquicos de atenção e memória.

Para trabalhar as habilidades auditivas ${ }^{13}$, em situações ou atividades que têm por objetivo desenvolver a discriminação auditiva, a criança deverá indicar se os sons, palavras, frases são iguais ou diferentes, começando por grandes diferenças e avançando com diferenças mais sutis entre os sons. Quanto ao reconhecimento dos sons, a autora salienta que na etapa introdutória do reconhecimento auditivo, o fonoaudiólogo apresente para a criança atividades de múltipla escolha, promovendo o reconhecimento de onomatopéias, vogais, consoantes, palavras e frases, e, na etapa avançada, as opções devem ser abertas e a criança deve, necessariamente, repetir o que ouviu. Já, para estimular a compreensão, a autora, anteriormente citada, recomenda que se comece de forma simples, com a criança respondendo a perguntas simples, como: "qual é seu nome?", "onde está o papai?"; e com o passar do tempo e com o avanço do processo terapêutico, habilidades para entender frases mais complexas, histórias, entre outros.

Durante o reconhecimento auditivo, esperase que a criança saiba: reconhecer as vogais, reconhecer os traços distintivos das consoantes, reconhecer as palavras e as frases. Em relação à compreensão, as autoras afirmam que as pessoas envolvidas com o trabalho terapêutico da criança devem estar com ela, auxiliando-a em sua tarefa mais difícil, que é a utilização da audição, pois é aí que se encontra uma alteração em seu sistema anatomofisiológico ${ }^{9}$.

Os estímulos verbais a serem utilizados nas tarefas e atividades para o desenvolvimento das habilidades auditivas podem ser de diferentes níveis de complexidade, dependendo de cada criança, da sua idade, do domínio da língua oral que apresenta e da habilidade auditiva já conquistada ${ }^{14}$. O desenvolvimento da função auditiva, em crianças com implante coclear e usuárias de próteses auditivas, tem similaridades, pois segue a mesma ordem de desenvolvimento (detectar, discriminar, reconhecer e compreender); porém, o que as difere, é o tempo e o esforço gastos para o desenvolvimento dessas habilidades, como, por exemplo, a criança implantada está apta a detectar os sons da fala algumas horas ou dias após a ativação dos eletrodos. Pode ser incidentalmente, enquanto a criança com prótese auditiva, muitas vezes, requer meses para desenvolver essa habilidade e de auxílio da terapia fonoaudiológica.
O objetivo desta pesquisa foi descrever e caracterizar as habilidades auditivas presentes em uma criança com perda auditiva e portadora do HIV inserida na abordagem oral. Para tanto, foi necessário: descrever o desenvolvimento auditivo da criança em questão; verificar a presença das habilidades auditivas no que se refere à detecção, discriminação, reconhecimento auditivo introdutório, reconhecimento auditivo avançado e compreensão; e caracterizar e descrever a forma em que as habilidades auditivas ocorrem.

\section{APRESENTAÇÃO DO CASO}

O presente estudo foi caracterizado como um relato de caso que verificou o desenvolvimento das habilidades auditivas de uma criança deficiente auditiva oralizada, portadora da Síndrome da Imunodeficiência Adquirida (HIV). A criança é do sexo masculino, tem sete anos, possui uma perda auditiva neurosenssorial de grau moderadamente severo a profundo, com curva descendente bilateralmente; faz uso de dispositivo auditivo da marca Siemens $₫$, modelo Phenix 303, com controles acionados bilateralmente e revisados semestralmente, além de frequentar atendimento fonoaudiológico na Clínica de Fonoaudiologia da Faculdade Estácio de Sá de Santa Catarina, no Estágio Supervisionado em Audiologia Educacional.

\section{Perfil do deficiente auditivo}

C. comparece à terapia fonoaudiológica na Clínica de Fonoaudiologia da Faculdade Estácio de Sá de Santa Catarina, há dois anos, para estimulação de linguagem, por apresentar deficiência auditiva.

O menor é adotado, e por esse motivo, a mãe adotiva não soube relatar os dados sobre a gestação e parto do mesmo. Aos seis meses de vida, o paciente foi diagnosticado como soropositivo e, desde então, toma medicamentos para controle do HIV.

Quanto ao desenvolvimento de C., a mãe adotiva relata que, com, aproximadamente, um ano de idade já falava as primeiras palavras, e que parou de desenvolver a fala com, aproximadamente, 18 meses. Já, o desenvolvimento psicomotor foi adequado, andando com 11 meses.

A mãe adotiva de $\mathrm{C}$. começou a perceber a deficiência auditiva do filho, com dois anos e meio de vida. A mesma relata que a criança teve otites de repetição dos dois aos quatro anos, começou fonoterapia aos quatro anos e foi protetizado aos cinco anos. C. tem uma deficiência auditiva do tipo neurosenssorial e de grau moderadamente severo a profundo com curva descendente. A responsável 
não soube relatar se existem familiares de C. com deficiência auditiva.

Para a coleta de dados foi realizada uma entrevista com a mãe do indivíduo da pesquisa, que foi adaptada do modelo de anamnese ${ }^{15}$. A mesma foi composta de 11 perguntas abertas, as quais abordam desde a gestação, até o desenvolvimento global da criança, com ênfase no desenvolvimento auditivo da mesma, e foi aplicada por meio de conversa informal com a mãe. As respostas foram anotadas em um papel, e foram transcritas, neste trabalho, em forma de texto.

Além da entrevista, foram observadas quatro sessões de fonoterapia com registro de vídeo, utilizando uma câmera digital da marca Mitsuca $₫$ modelo DC 7325BR com resolução de 7.0 megapixels. Para a análise dos dados, foram selecionadas as situações terapêuticas que melhor exemplificam as habilidades auditivas que foram transcritas. A partir destas, a pesquisadora utilizou um quadro que permitiu avaliar a presença dessas habilidades, sendo elas: detecção, discriminação, reconhecimento auditivo introdutório, reconhecimento auditivo avançado e compreensão.

Nesta pesquisa, as habilidades auditivas foram consideradas presentes, quando adquiridas, por completo, pelo paciente; portanto, se a habilidade auditiva ainda se encontrava em processo de desenvolvimento, esta foi considerada como ausente para o preenchimento do quadro.

Na primeira sessão, foram analisadas as habilidades auditivas de detecção e discriminação. Para a primeira habilidade, a cada som novo que surgiu na sala, chamou-se a atenção da criança para o mesmo, além de outros sons serem produzidos pela terapeuta para que a criança detectasse.

Para se verificar a habilidade de discriminação, primeiramente foram apresentados dois sons instrumentais distintos (tambor e sino), e a criança teve que diferenciá-los por meio de associação do som com peças do jogo ábaco, em que cada cor das peças equivalia a um instrumento. Dessa forma, o tambor equivaleu à cor verde e o sino à cor amarela. Acertando essa questão, o grau de dificuldade aumentou, apresentando ao paciente, fonemas, palavras e frases.

Na segunda sessão, foi avaliada a presença do reconhecimento auditivo, que se dá em duas etapas. A primeira é o reconhecimento auditivo introdutório, que foi avaliado em conjunto fechado. Para isso, foi gravado um CD com os seguintes sons: animais (cavalo, gato, cachorro, passarinho, leão e boi); sirene de polícia; coração batendo; tambor; e sino. Esses sons foram apresentados ao paciente por meio de um aparelho de som da marca Sony ${ }^{\circledR}$. A criança teve que apontar os brinquedos, que se encontravam em cima da mesa, que se correspondiam aos sons, anteriormente citados.

Para a etapa avançada do reconhecimento auditivo, foi contada a história dos três porquinhos. Após ouvi-la, a criança teve que interpretá-la, demonstrando, ou não, o reconhecimento da história infantil. Como auxílios para a interpretação, foram utilizados os seguintes materiais: três casinhas, sendo elas de palha, madeira e material; dedoches (fantoches para dedos) dos três porquinhos; e, um fantoche do lobo mau. Nesta sessão também foi analisado e descrito o aspecto simbólico da criança.

$\mathrm{Na}$ terceira sessão, a habilidade auditiva de compreensão foi verificada. Nesta, a criança teve que responder perguntas simples como: "qual seu nome?", "onde está o papai?" e "onde você mora?". A estratégia utilizada foi a realização de uma entrevista utilizando um microfone e uma filmadora de brinquedo.

Também foi elaborada uma atividade com o auxílio de produtos de supermercado (ovo, alface, leite, sabão em pó, suco, achocolatado, sabonete, maçã, detergente e açúcar), em que a criança simulou uma visita a este estabelecimento, devendo compreender as ordens da terapeuta para realizar as compras.

$\mathrm{Na}$ quarta sessão, a fonoterapia foi direcionada às quatro habilidades auditivas. Foi elaborada uma estratégia que englobou os afazeres rotineiros da criança, como colocar roupa, reconhecer partes do corpo, diferenciar os sexos, reconhecer números e onomatopéias. Para tanto, foram coladas figuras de dois meninos e duas meninas na parede e a criança teve que colar roupas de papel nessas figuras, obedecendo às ordens da terapeuta. Também foi utilizado um jogo de memória de números e quantidades, em que o paciente deveria falar o número e qual o objeto que representava a sua respectiva quantidade. Nessa sessão, foram criadas situações auditivas em que a criança teve que detectar, discriminar, reconhecer e compreender o som.

Após a coleta de dados conforme os procedimentos citados anteriormente, estes foram analisados qualitativamente. Devido a questões éticas, o indivíduo que participou da pesquisa não teve o seu nome publicado neste trabalho, sendo identificado como C., para preservar a identidade do mesmo.

O projeto de pesquisa foi submetido ao Comitê de Ética da Faculdade Estácio de Sá de Santa Catarina (processo n. 006/2008), e após aprovação e assinatura do "Termo de Consentimento Livre e Esclarecido", em 19 de maio de 2008, foram coletados e analisados os dados contidos nesta pesquisa.

A análise de dados foi realizada de forma qualitativa. 
Os resultados foram apresentados e discutidos de acordo com o referencial teórico existente na área do tema pesquisado. Pode-se, no entanto, definir esse processo como uma sequência de atividades, que envolve descrição de dados, a categorização dos mesmos, sua interpretação e a redação do texto final.

\section{RESULTADOS}

A presente categoria se refere à exibição dos momentos em que as 'habilidades auditivas' apareceram, transcrevendo as sessões de fonoterapia observadas e filmadas.

\section{Habilidades auditivas}

Nesta seção, estão expostos os momentos em que as habilidades auditivas apareceram. A habilidade de detecção foi verificada na primeira e na quarta sessão. Na primeira, observou-se que quando um cachorro latiu na rua, chamando a atenção da criança, ela parou de realizar a atividade que estava desempenhando (tocar no tambor), olhou para a janela e imitou o som do cachorro. A terapeuta enfatizou a ação do menor, apontando para o ouvido e falando que aquele som se referia a um cachorro. O paciente ficou em silêncio, até o latido parar. Nesse momento, ele pegou o tambor novamente e começou a tocar.

Também se observou a habilidade de detecção auditiva na quarta sessão, em que o paciente escutou a fala de uma estagiária que se encontrava realizando fonoterapia na sala ao lado. O paciente apontou para o ouvido e olhou para a parede, fazendo gestos com as mãos, significando a pergunta de qual era aquele som. A terapeuta levou o paciente para a sala ao lado para mostrar ao menor qual era o significado daquele som (uma pessoa falando).

A habilidade de discriminação pode ser observada presente na primeira sessão, na qual a terapeuta realizou um condicionamento com um jogo de encaixe ao tocar os sons instrumentais. O som do tambor representava a peça verde e o som do sino, a peça amarela. A terapeuta tocou os instrumentos, sem pista visual, intercalando-os e o paciente encaixou, corretamente, todas as peças.

Em seguida, o paciente realizou a discriminação de vogais. Já que ele tem dificuldades em se expressar oralmente, falando se os sons são iguais ou diferentes, foi realizado, com apoio visual das vogais escritas, avaliando, também, o reconhecimento auditivo. A terapeuta, com um papel em frente da boca para omitir a pista visual, pronunciou as cinco vogais de forma intercalada, sendo que o paciente não discriminou e reconheceu apenas a vogal I, apontando para a vogal E. Todas as vogais foram repetidas duas vezes, para confirmação das respostas.

A discriminação de consoantes, palavras e sentenças não pode ser realizada pela dificuldade de compreensão do paciente.

O reconhecimento auditivo foi avaliado na segunda e na quarta sessão. Somente se mostrou presente a etapa de reconhecimento auditivo introdutório, em que foram colocados sobre a mesa brinquedos de animais (cavalo, gato, cachorro, passarinho, leão e boi); um carro de polícia; um coração; um tambor e um sino. Em um CD foram gravados os sons correspondentes a esses brinquedos, que foram mostrados ao paciente, por meio de um aparelho de som da marca Sony®.

O paciente sentou-se em frente aos brinquedos, enquanto a terapeuta acionava os sons. O primeiro foi o cavalo, seguido pelo leão, passarinho, cachorro e gato. O paciente reconheceu todos esses sons, colocando a mão sobre os brinquedos. O próximo som foi do boi, porém o paciente não reconheceu. $A$ terapeuta mostrou novamente o som do boi. Houve confirmação da ausência do reconhecimento desse som. A terapeuta passou para os sons: sirene de polícia e sino, que foram, rapidamente, mostrados pelo paciente; e o tambor, que foi confundido com o carro, não sendo reconhecido.

Para analisar a etapa avançada do reconhecimento auditivo, por meio de conjunto aberto, a estratégia utilizada foi a leitura de uma história infantil (Os três porquinhos) com, posterior interpretação da mesma. Sobre a mesa, foram colocadas as casinhas, dedoches dos três porquinhos e um fantoche do lobo mau.

Primeiramente, a história foi contada ao paciente, mostrando para ele as figuras do livro, para que o mesmo obtivesse conhecimento do conto. Em seguida, foi solicitado que o paciente recontasse a história. Ele não o fez, pegando o lobo mau e brincando com as casinhas que estavam sobre a mesa.

A terapeuta começou a recontar a história, obtendo, novamente, a atenção do paciente. No momento da narrativa, em que o primeiro porquinho constrói a sua casa de palha, a terapeuta perguntou ao paciente qual era a respectiva casa. $\mathrm{C}$. apontou para a casa certa, reconhecendo e compreendendo a pergunta feita pela terapeuta. Porém, a etapa do reconhecimento auditivo avançado não está completa, como se pode observar no momento em que a terapeuta contou que o lobo mau bateu na porta, e a terapeuta solicitou que $C$. realizasse a ação.

E o paciente ficou esperando a terapeuta continuar contando. Ela, por sua vez, pegou na mão de $\mathrm{C}$. que estava com o fantoche do lobo mau e bateu na porta da casa de palha, emitindo o som 
"toc, toc, toc". Com a outra mão, a terapeuta pegou o porquinho e falou "Quem é?", simulando a fala do porquinho.

Nesse momento, o paciente pegou a casa e jogou no chão, copiando a foto do livro que mostrava a casa de palha caída, após ter sido soprada pelo lobo mau, não obedecendo à ordem da história, na qual o lobo mau deveria se identificar e ameaçar o porquinho que iria soprar até derrubar a casa, se este não abrisse a porta.

O reconhecimento auditivo avançado, assim como a compreensão se fazem ausentes no momento em que a terapeuta solicita que o paciente identifique as partes do corpo, e na estratégia de entrevista, quando a terapeuta pergunta qual é o seu nome, a sua idade e onde mora, e o paciente responde com fala idiossincrática, pois sabia que deve falar quando é colocado um microfone na sua boca, porém não sabe o que falar, emitindo sons sem significado algum para quem está ouvindo.

$\mathrm{Na}$ terceira sessão, quando se objetivou observar a presença da compreensão, pode-se perceber que esta habilidade está em processo de desenvolvimento, visto que o paciente não responde as ordens da terapeuta, que solicita que este comprasse os produtos do supermercado. Assim como na quarta sessão, quando a terapeuta realizou ordens de colocar roupas em bonecos, e o paciente respondeu pegando a roupa certa e colocando no boneco errado e vice e versa.

Com isso, a Figura 1 fica preenchida da seguinte forma:

\begin{tabular}{|c|c|c|}
\hline & Presente & Ausente \\
\hline Detecção & & \\
\hline Discriminação & & \\
\hline Reconhecimento Auditivo Introdutório & & \\
\hline Reconhecimento Auditivo Avançado & & \\
\hline Compreensão & & \\
\hline
\end{tabular}

Figura 1 - Habilidades auditivas

\section{DISCUSSÃO}

Com relação ao desenvolvimento da linguagem do paciente, esta se encontra com um déficit de desenvolvimento, mostrando um distúrbio de linguagem avançado para a idade do paciente. Como visto no perfil do deficiente auditivo, este frequenta terapia fonoaudiológica há dois anos. Moret ${ }^{14}$ cita a abordagem Auri-Oral como um método de atendimento da criança deficiente auditiva, com a finalidade de auxiliar a criança a adquirir a linguagem oral e de integrar a audição a sua personalidade, devendo-se começar o trabalho o mais precocemente possível para alcançar resultados melhores no desenvolvimento da mesma.

Cavalcante ${ }^{16}$, por meio de estágios para a aquisição da linguagem, relata que entre um e dois anos de idade a criança consegue emitir as primeiras palavras e seu vocabulário começa a ser construído. No caso de C., começou a desenvolver o seu léxico, porém este parou de evoluir. A mãe adotiva do menor cita que o motivo desse retrocesso no desenvolvimento da fala é psicológico, porém, alguns autores ${ }^{7,14}$ relatam que a privação sensorial auditiva, nos primeiros anos de vida, impede ou dificulta a aquisição da linguagem oral.
Visto que C. faz uso de medicamentos para o controle do vírus HIV, pesquisadores ${ }^{2,3,17}$ alertam que grande quantidade de medicamentos ingeridos pelo portador pode ser o fator causal dessa alteração audiológica. Soares et al ${ }^{18}$ sugerem a inserção de testes audiológicos na bateria de exames que o portador do vírus da imunodeficiência humana deve realizar, e Rezende et al ${ }^{3}$ enfatizam a importância do diagnóstico precoce da deficiência auditiva em portadores deste vírus, tornando-se um fator importante para o controle da doença, para começar, o quanto antes, a fonoterapia e a indicação e adaptação de próteses auditivas.

Miller-Hansen et al ${ }^{19}$ citam o AASI como sendo um recurso de extrema importância para a reabilitação do deficiente auditivo. Para o grau de deficiência auditiva que o paciente apresenta, cita-se ${ }^{6}$ que a criança tem dificuldades em compreender a fala, podendo afetar o desenvolvimento da linguagem. Na perda profunda há apenas restos de audição e o uso da prótese auditiva somada à fonoterapia e uma ajuda contínua dos familiares, permitirão que ela desenvolva a fala, linguagem e o aprendizado escolar, por meio da audição.

A primeira habilidade que o deficiente auditivo adquire é a detecção e, consequentemente, deve 
ser a primeira habilidade a ser trabalhada na fonoterapia, em que o fonoaudiólogo deve chamar atenção para a presença e ausência do som. Pietrobon ${ }_{12}$ relata que, assim que a criança consegue detectar o som, o trabalho fonoterapêutico deve visar ao desenvolvimento da habilidade auditiva de discriminação, o qual deve estimular a criança a diferenciar os seguintes sons: vogais, traços distintivos de consoantes, palavras, frases e curvas melódicas. $\mathrm{O}$ paciente conseguiu discriminar os traços distintivos de dois instrumentos musicais e as vogais. A discriminação de três instrumentos não foi realizada pelo paciente, devido à dificuldade de associação destes com a cor da peça do jogo, e, em consequência da grande dificuldade de compreensão do paciente, não foi possível realizar a diferenciação de consoantes, palavras e sentenças.

Pesquisadores ${ }^{8}$ verificaram em seu estudo que a discriminação auditiva está diminuída em crianças com perda de audição quando comparadas a crianças ouvintes.

Pode-se verificar a presença da habilidade de reconhecimento auditivo introdutório. Nota-se que o paciente reconhece onomatopeias, pegando, corretamente, os objetos correspondentes ao som ouvido, não sendo reconhecido, apenas, o som do tambor, que foi confundido com o som do cachorro. Isso pode ocorrer por dois motivos: ou o paciente não conhece o som do tambor, ou pelas características acústicas do aparelho de amplificação sonora, o som pode ser distorcido, e, por ser um som grave parecido com o do cachorro, pode ser confundido por este.

Porém, existem situações que demonstram a dificuldade do paciente em reconhecer ordens em um contexto aberto. Quando mostrado ao paciente, com o auxílio visual, em que a terapeuta se posiciona na frente do paciente para fazer a pergunta, autorizando que este realizasse leitura orofacial, C. conseguiu explanar o que a terapeuta sugeria, porém, não se pode defender que houve reconhecimento auditivo avançado.

C. é capaz de reconhecer as vogais, reconhece a fonte geradora do som e localiza a fonte geradora do som. Porém, os demais aspectos responsáveis pelo reconhecimento não são demonstrados por C., concluindo que a habilidade auditiva de reconhecimento não está completa, mostrando presente, somente, a habilidade de reconhecimento auditivo introdutório, e, ausente, a habilidade de reconhecimento auditivo avançado.

Pode-se perceber que a habilidade auditiva de compreensão está com um atraso notável em seu desenvolvimento, e, portanto, classificada como ausente. Visto que o paciente não respondeu a perguntas simples de sua rotina, como o seu nome e sua idade, assim como não responde a ordens complexas. Enumo ${ }^{20}$ refere que o trabalho com a compreensão deva passar por estágios, partindo de uma forma mais simples, como responder o seu nome e onde está o papai, até chegar ao estágio de compreender sentenças mais complexas e histórias.

A compreensão de linguagem envolve uma série de fatores, entre eles: o vínculo entre mensagem e contexto; o conhecimento que a criança tem da linguagem; a memória sequêncial; os conhecimentos gramaticais; o domínio dos conceitos e a vivencia social da criança, nas mais diferentes dimensões 21,22 .

\section{CONCLUSÃO}

Com base na literatura pesquisada e nos achados descritos, pode-se concluir que as habilidades auditivas de detecção, discriminação e reconhecimento auditivo introdutório estão presentes no sujeito pesquisado e as habilidades auditivas de reconhecimento auditivo avançado e compreensão estão em processo de desenvolvimento, e, portanto, classificadas como ausentes.

Com relação ao desenvolvimento auditivo, verificou-se que a demasiada ingestão de medicamentos para o controle do HIV pode ter sido o fator causal da deficiência auditiva, e que o diagnóstico tardio, assim como a demora para a protetização, estão diretamente relacionados ao atraso do desenvolvimento das habilidades auditivas da criança, o que influencia, diretamente, na aquisição e desenvolvimento da linguagem oral.

Dessa forma, os objetivos da pesquisa foram alcançados e sugere-se que mais pesquisas que designem descrever a decorrência das habilidades auditivas nos deficientes auditivos portadores de HIV sejam efetuadas, uma vez que o tema contribuirá para o acréscimo de informações diagnósticas no tratamento fonoaudiológico. 


\section{ABSTRACT}

Background: hearing abilities of HIV carrier child. Procedures: children are likely to have several deficits in language development if hearing loss, as well as its etiology, has not been precociously detected. High doses of drugs taken by HIV carriers in order to control the disease have been responsible for increasing hearing impairment levels. During the process of hearing development, an individual passes through acquisition of auditory skills, which occurs in different steps of the therapeutic process, as follows: detection, discrimination, introductory identification, advanced identification and comprehension. This research is a case report, which aims to describe and characterize auditory skills in a hearing-impaired child. The child was a hearing device user and attended Speech-language therapy at the clinic located in the Estácio de Sá University Campus, in Educational Audiology supervised apprenticeship. Four speech therapy sessions were filmed for data collection, with the objective of observing presence or absence of auditory skills. Results: auditory detection skills, discrimination and introductory identification were found in the individual. Advanced identification and comprehension were found in development stage, thus, they were absent. Conclusion: the development of auditory skills is crucial to oral language acquisition by the hearing impaired.

KEYWORDS: Hearing Loss; HIV; Language

\section{REFERÊNCIAS}

1. Word Health Organization. Deafness and hearing impairment. Fact Sheet $\mathrm{n}^{\circ}$ 300; march 2006. Disponível em: URL: http://www.who.int/ mediacentre/factsheets/fs300/en/index.html

2. Jacob LCB, Aguiar FP, Tomiasi AA, Tschoeke SN, Bitencourt RF. Monitoramento auditivo na ototoxidade. Rev Bras Otorrinolaringol. 2006; 72(6):836-44.

3. Vieira EP, Tochetto TM, Pedroso FS. Indicadores de risco para a deficiência auditiva infantil: infecções congênitas. Fono Atual. 2005; 8(32):61-7.

4. Rezende CEB, Rodrigues REC, Haddad L, YoshimuraR, RapoportPB. Manifestaçõesotológicas em criança com síndrome da imunodeficiência adquirida. Rev Bras Otorrinolaringol. 2004; 70(1):129-32.

5. Freitas CD, Costa MJ. Processo de adaptação de próteses auditivas em usuários atendidos em uma instituição pública federal - parte I: resultados e implicações com o uso da amplificação. Rev Bras Otorrinolaringol. 2007; 73(6):744-51.

6. Colunga JCM, Méndez JCA, Villarreal JMC, Zapico MJA, Estrada CM, Alvarez MLF, et al. Despistage de la hipoacusia neonatal: resultados después de 3 años de iniciar nuestro programa. Acta Otorrinolaringol. Esp. 2005; 55(1):55-8.

7. Kaminski JM, Tochetto TM, Mota HB. Maturação da função auditiva e desenvolvimento da linguagem. Rev Soc Bras Fonoaudiol. 2006; 11(1):17-21.

8. Portugal AC, Capovilla FC. Triagem audiológica na primeira série: efeitos de perda auditiva sobre vocabulário, consciência fonológica, articulação da fala e nota escolar. Cad Psicopedagog. 2002; 1(2):60-97.

9. Bevilaqua MC, Formigonni GMP. O desenvolvimento das habilidades auditivas. In: Bevilaqua MC, Moret ALM. Deficiência auditiva: conversando com familiares e profissionais de saúde. São José dos Campos: Pulso; 2005. p. 179-201.

10. Padovani CMCA, Teixeira ER. Do balbucio à fala: reflexões sobre a importância das atividades linguísticas iniciais e o desenvolvimento da linguagem oral em crianças com deficiência auditiva. Rev Dist Comun. 2005; 17(1):45-54.

11. Scaranello CA. Reabilitação auditiva pósimplante coclear. Medicina. 2005; 38(3/4):273-8.

12. Pietrobon C. Aprendizado das habilidades auditivas. Fonoaudiologos.net [hompage na internet] Guia de fonoaudiólogos no Brasil e artigos de fonoaudiologia, 2007. [atualizado em 14 set. 2009] Disponível em: URL: http://<www. fonoaudiologos.net>

13. Brazorotto JS. A terapia fonoaudiológica da criança surda. In: Bevilaqua MC, Moret ALM. Deficiência auditiva: conversando com familiares e profissionais de saúde. São José dos Campos: Pulso; 2005. p. 203-25.

14. Moret ALM. Princípios básicos da habilitação da criança deficiente auditiva com implante coclear. In: Bevilaqua MC, Moret ALM. Deficiência auditiva: conversando com familiares e profissionais de saúde. São José dos Campos: Pulso; 2005. p. 225-34.

15. Nicola M, Cozzi T. Manual de avaliação fonoaudiológica. São Paulo: Revinter; 2004. 
16. Cavalcante F. Família, subjetividade e linguagem: gramáticas da criança "anormal". Ciênc. Saúde Coletiva. 2006; 6(1):125-37.

17. Matas CG, Leite RA, Magliaro FCL. Avaliação audiológica e eletrofisiológica em crianças portadoras da síndrome da imunodeficiência adquirida. Acta ORL. 2005; 23(4):160-4.

18. Soares RRL, Reis ACMB, Silva FP. Achados audiológicos em indivíduos portadores do vírus HIV. [trabalho de conclusão de curso] Franca (SP): Universidade de Franca; 1998.

19. Miller-Hansen DR, Nelson PB, Widen JE, Simon SD. Evaluating the benefit of speech recoding hearing aids in children. Am J Audiol. 2005; 12(2):106-13.
20. Enumo SRF. Avaliação assistida para crianças com necessidades educacionais especiais: um recurso auxiliar na inclusão escolar. Rev Bras Educ Espec. 2005; 11(3):335-54.

21. Guarda NS, Deliberato D. Caracterização dos enunciados de um aluno não-falante usuário de recurso suplementar de comunicação durante a construção de histórias. Rev Bras Educ Espec. 2006; 12(2):269-88.

22. Saupe R, Budó MLD. Pedagogia interdisciplinar: "educare" (educação e cuidado) como objeto fronteiriço em saúde. Texto Contexto Enferm. 2006; 15(2):326-33.

DOI: 10.1590/S1516-18462009005000065

RECEBIDO EM: 02/07/2009

ACEITO EM: 02/11/2009

Endereço para correspondência:

Raquel Fleig

Rua Júlio Dias, 605/501

Florianópolis - SC

CEP: 88080-060

E-mail: fonofleig@gmail.com 